\title{
The role and tasks of the support mats in construction of catalytic converters
}

The purpose of support mats used in catalytic converters as connecting element between the ceramic core and the metallic converter housing has been presented in article. The functional requirements and operating conditions have been discussed as well as support mat types and manufacturing methods. The support mat choice and basic design features have been also presented.

Key words: support mat, exhaust system, catalytic converter, amorphous fibre, polycrystalline fibre

\section{Introduction}

Different types of vehicles powered by internal combustion engines are from more than 100 years the primary means of transportation by land, water and air. A special role is played here by vehicles designed to land transport of people and goods and their operation affect the environment and human organisms directly.

Due to this reason, in the early 70 s was introduced the limitation of toxic components in vehicle exhaust gases. Currently various types of catalytic converters in exhaust systems with spark ignition and compression ignition engines are used. The efficiency of these aftertreatment systems depends on the placement in the vehicle exhaust system depending mainly on the system geometry $[1,2,3]$.

In the automotive industry the first elaborated and serial produced in 70 s and 80 s exhaust gas cleaning systems were oxidizing catalytic converters.

The three-way catalytic converter (TWC) in combination with a lambda sensor has become standard in vehicles with petrol engines. Due to an enhanced limitation of particle emissions the introduction of Gasoline Particulate Filters (GPFs) is on-going process. In the case of diesel engines, Diesel Oxidation Catalyst (DOC) and Diesel Particulate Filter (DPF) are standard to fulfil the carbon monoxide (CO), unburned hydrocarbons (HC) and soot particle limits. Enhanced NOx emission limitations require technologies like NSC (NOx trap catalyst) or the Selective Catalytic Reduction (SCR) technology.

The relevant regulations concerning both the conditions and operation lifetime, determine effectiveness of action of each system of exhaust gas purification. Hereby it has to be considered that these components have to fulfil challenging durability requirements. The efficient catalyst system operation has to be ensured through the entire life of the vehicle (for example in Europe - 12 years, in USA - 15 years). Operation lifetime is determined mostly by the design and installation of all elements, even those that from the viewpoint of objectives have additional aims. Such elements can include e.g. ceramic fibre mats whose function is to fix the core in the catalytic converter housing $[4,6]$.

\section{Operating conditions of catalytic converters}

For designing a robust converter layout it is mandatory to know the boundaries of the operating conditions. These are mainly:

- vibration - coming from the engine (high frequency) and interaction between terrain and vehicle body (low frequency),
- exhaust gas flow and temperature,

- chemical factors like exhaust gas condensate, ammonia or urea.

The inclusion of these three groups of factors has the greatest impact on design and selection of materials used for individual elements of the catalytic converter [1].

Generally the exhaust system can be divided into a so called "cold end" and a "hot end". The cold end comprises mainly the vehicle underbody pipe routing, silencers and the tailpipe. The hot end contains mainly exhaust aftertreatment components which are located close to the engine. The exhaust gas temperature up to $1000^{\circ} \mathrm{C}$ can be achieved what put high requirements to all materials in this area, e.g. steel parts, support \& insulation materials.

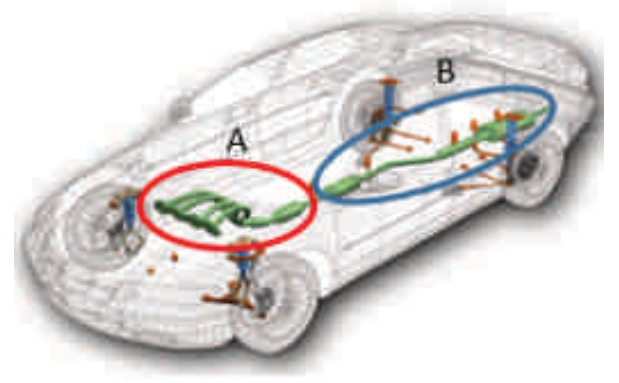

Fig. 1. Location of the exhaust system elements in a passenger car; A "hot end", B - "cold end" [4]

High working temperature is one of the main factors that need to be taken into account while designing the catalytic converter, because it causes the formation of thermal stresses and changes in the structure of construction materials as well as their surface. Especially important is the heating-up period of the catalytic converter during which variable thermal stresses dependent on the heating rate and different characteristic of the materials used to construction of the catalytic converter are formed. The impact of thermal stress on components of the catalytic converter associated with changes in the geometry of the individual segments cause stresses and decrease of mechanical properties. It can cause micro- and macro-cracks which occur mostly at the transition area between heat affected zone (HAZ) of the weld seam and base material (significant difference in mechanical properties). The effect is enlarged by the mechanical vibrations coming from the suspension, the manifold gas pressure vibrations coming from the respective cylinders of the engine and the vibration of the entire exhaust 
system comes from the irregularities of the surface on which the vehicle is moving. External vibrations are partially suppressed by the spring elements and elastic elements which mount the exhaust system under the car body, whereas the vibration inside the catalytic converter is suppressed mainly by a support mat. All of the above types of vibrations in combination with weakened mechanical properties of the material resulting from the manufacturing process, can cause the formation of cracks and destruction of the components of the catalytic converter $[2,5]$.

The TWC and DOC/DPF-assemblies are mainly located close to the engine whereas SCR-converters and GPFs are mainly located in a vehicle underbody position. For future emission levels these components will also be moved closer to the engine.

One of the structural components of catalytic converters which are particularly vulnerable to damage as described above is the core. Improper selection of support mats can lead to a shift of the core inside the catalytic converter housing and at worst case can lead to damage of it. In this case the appropriate choice of the mat material and the arrangement of the core in the reactor have a significant impact on the length of its life [4].

\section{Support mats fibres overview}

The operating conditions of the support mat used in production of catalytic converters create specific material design requirements.

The most frequently used materials to manufacture of support mats are inorganic synthetic fibres.

The fibres are divided into two groups:

1. Amorphous - mainly used for the production of support mats:

- Mineral wools - e.g. Alkaline Earth Silicates (AES). These fibres are used for the production of biosoluble intumescent support mat. According to the regulations, both European and German, these fibres are classified as 0 i.e. "green fibres". AES fibres mainly consist of the following components: $\mathrm{CaO}$, $\mathrm{MgO}, \mathrm{SiO}_{2}, \mathrm{ZrO}_{2}$. The maximum allowed application temperature for this type of fibres is up to $850^{\circ} \mathrm{C}[1]$

- Refractory ceramic fibres (RCF) - belong to the classification 1B which is classified in Europe as potentially carcinogen. The use of this fibres type is restricted in EU. The chemical composition of RCF is based on $\mathrm{SiO}_{2}$ and $\mathrm{Al}_{2} \mathrm{O}_{3}$ in proportions around 50:50\%. The application temperature limit for this type of fibre is $1100^{\circ} \mathrm{C}$ [4].

2. Polycrystalline (PC) - the example of such fibres used in the production of support mats is:

- Fibre consisting alumina belonging to subgroup oxide fibres. According to EU regulations these fibres belong to the category 0 - "green fibres", while according to German regulations these fibres belong to group 3 -suspected of being carcinogenic. PC fibres are made mainly of $\mathrm{Al}_{2} \mathrm{O}_{3}$ (more than $70 \%$ ) and the remaining part of $\mathrm{SiO}_{2}$. The maximum permissible temperature for this type of fibre is $1100^{\circ} \mathrm{C}$ [4].

Main manufacturing processes for fibres are produced by two methods (Fig. 2):
1. Melt spinning process - widely used in industry. Material from which fibre is produced is melted inductively in the crucible made of quartz or ceramics. The molten material is sprayed on a cooled roller rotating at a constant angular velocity. Cooling can take place on one roller or two rolls rotating in opposite directions. This method can produce amorphous fibres having a diameter of from 1 to 6 microns.

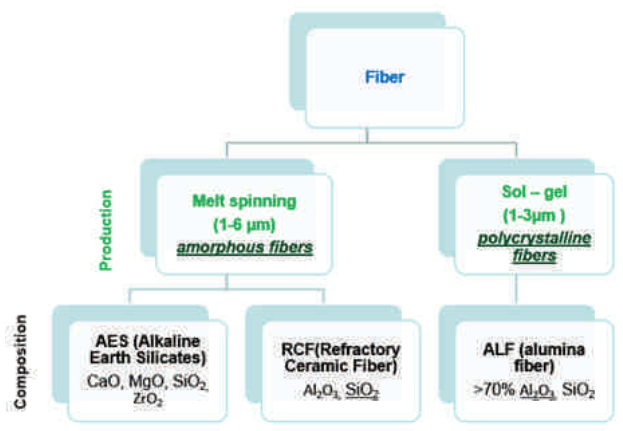

Fig. 2. Fibres materials used for manufacture of support mats [4]

By use of this method two types of amorphous fibres can be produced:

- Alkaline Earth Silicates (AES)

- Refractory Ceramic Fibre (RCF)

2. Method sol-gel - is to generate a gel from the colloidal solution (sol). Very important for this process is that the last three steps of heat treatment presented in Fig. 3 have to be conducted right after each other.

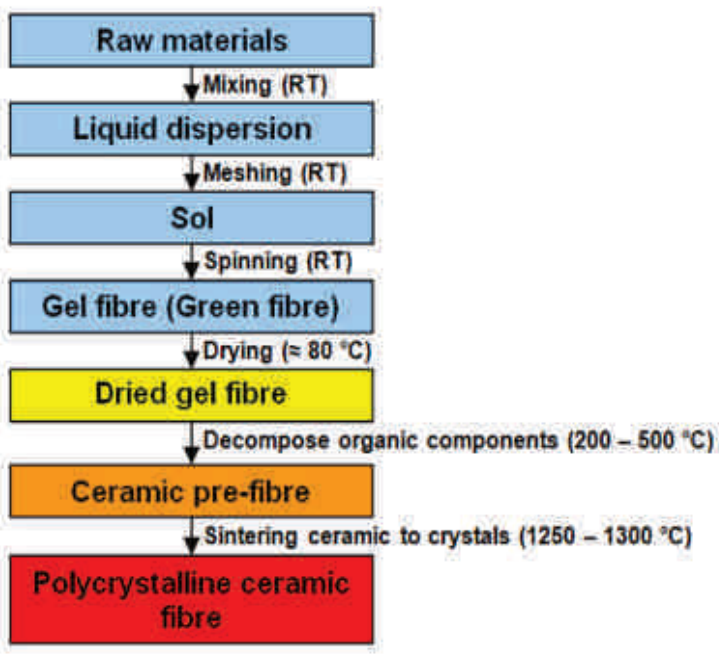

Fig. 3. Sol-gel process [4]

This method is mainly used for the production of polycrystalline fibres; the advantage is very constant and narrow fibre diameter of approximately 3 micrometres [4].

\section{The support mat manufacturing process}

Due to the build of the inner structure, the support mats are divided into three basic types:

1. Needled mat - needle felting method in which mat is formed in a dry air-lay process and then needled. In the first step, the bulk material is transformed into a blanket 
of constant thickness through air-lay. Air-lay machines produce the blanket by disintegrating the fibre bulk with an air stream and settling it on a rotating drum. After the needling the felt is heat treated to convert the green solgel fibre into a ceramic fibre. The heat-treated mat is then cut in pieces and soaked in binder whereby the surplus is removed by a vacuum. After the bonding of the binder the product is cut into its final shape.

2. Paper mat - the earliest development of support mats. The paper mat production process starts with mixing fibres, binder raw material and a liquid to obtain a dispersion of slurry. The mat is then dried in an oven at moderate temperatures whereby the binder starts to bond the fibres together. The dried mat is then winded up to a big roll called jumbo. In case of production of blankets they are stacked upon each other. In the next step the blankets or jumbo rollers are cut with stamps into the shape of the final product.

3. Vermiculite mat - intumescing mats incorporate besides fibres also vermiculite whereby the content of vermiculite can be up to $65 \%$ mass. Fibres and vermiculite are bound together in a binder matrix. To produce intumescent mats vermiculite is added as a fourth component [4].

\section{Support mat choice and layout}

Main parameters for the right support mat choice and layout are:

- Local market regulations concerning fibre type permitted to use for catalytic converter support mat. In the EU support mat should belong to classification group of 0 i.e. "green fibre".

- A very important parameter in the selection of the support mat is operating temperature of the catalytic converter. The choice is dependent not only on the place in which a catalytic reactor is mounted (near or far from the engine), but also on the exhaust gas temperature, which is dependent on the type and method of operation of the engine used.

- The borders of the mounting density called GBD (Gap Bulk Density) advised by the supplier.

- Safety factor of the designed support mat plate. It should be greater than or equal to 1 which means the system is robust.

$=$ Customer requirements - in many cases customer has own support mat supplier.

- Support mat costs [4].

The support mat is placed between the catalytic reactor and the core. The main objective is to maintain the core in a fixed position and to prevent it from movement.

Based on the parameters mentioned above a layout calculation has to be performed to determine the required holding force of the mat according to allowed pressure to avoid destroying the fragile ceramic substrate or the support mat itself.

Beside the holding function the support mat acts as a bypass sealing and as an insulation material to keep the low outer housing surface temperature. The support mats are used exclusively to ceramic cores (Fig. 4), which are used as an input to the catalytic converter more often than the corresponding metal cores. The combination of ceramic substrate and support mat is good compromise between component costs and functional aspects.

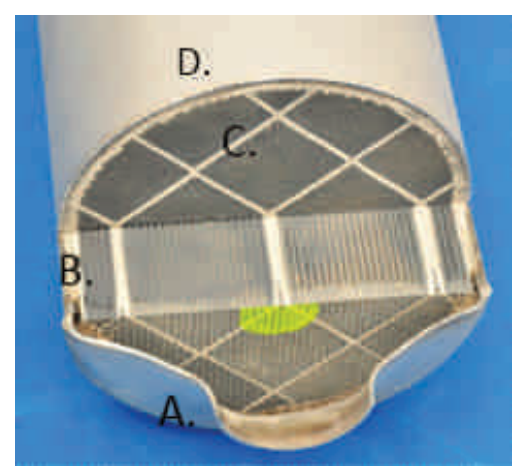

Fig. 4. Cross-section through a catalytic converter: $\mathrm{A}-$ cone, $\mathrm{B}-$ support mat, $\mathrm{C}-$ substrate, D - housing [4]

The disadvantage of ceramic cores is their fragile structure, worse thermal conductivity (longer heating time) and lower allowable temperature of their operation. For example, the TWC reactor operating temperature is in the range of $400-900^{\circ} \mathrm{C}$ because in this temperature range the coating have the best performance from the point of view of the operation of the catalytic converter $[2,3]$.

Depending on the core size, holding and surface temperature requirements the support mat thickness can vary. Therefore different ways of installation are available:

- One layer of the support mat (Fig. 5) - in this method the support mat is wrapped around the core and then subjected to a stuffing process. The canning technology is the most commonly used method.

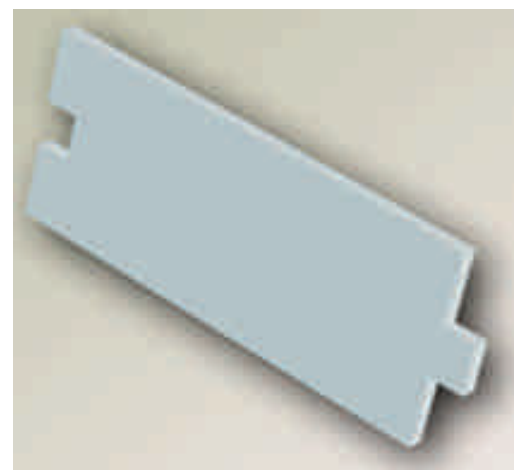

Fig. 5. Support mat [4]

- Two layers of the support mat - this concept is used in case of a big support mat gap, e.g. due to enhanced surface temperature or holding requirements or big core diameter i.e. heavy duty applications. Disadvantageous is the increased handling effort due to the double layer.

- Multi wrapping mat - the process is applied in the case of a large gap. In the case of a single layer the holding force is not large enough to maintain the core. This applies to the support mat where the supplier does not offer a large enough dimension. In this process the core is wrapped two to four times with the support mat. Such prepared system is inserted into the steel housing which 
has a constant diameter. This method is used in production of cylindrical catalytic converters for trucks [4].

An important issue in the case of the support mat is vibration as well as mechanical and thermal impact of exhaust gases that can lead to erosion. Erosion products in the form of detached fibres of the support mat can lead to partial or complete clogging of the channels of the core. Erosion of the support mat can take form of thin channels, by which exhaust gases can bypass the core. Any type of mat mass loss reduces its thickness and lead to changes in the structure of the mat. It can be a cause of displacement or damage of the substrate.

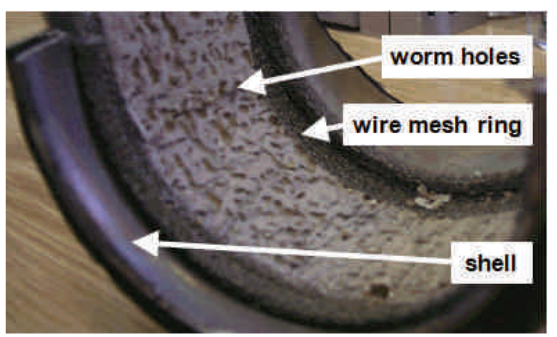

Fig. 6. Worm-holing effect by solid non fibrous material in the mat [4]

Proper support mat mounting and compression of it in the housing is very significant in case of intumescent mats. When the intumescent mat is compressed not enough the so called "worm-holing" effect (Fig. 6) can appear.

"Worm-holing" - occurs when lose particles like vermiculate in support mat can vibrate and oscillate freely after mounting the mat in housing.
Those particles damage the mat what cause erosion, less holding force and danger of not supporting the core properly. Due to a good progress in support mat design and the layout process it is possible to ensure reliable and durable construction in terms of holding function and erosion resistance [4].

\section{Summary}

The support mat is an important structural component of the design of aftertreatment systems which ensures a robust and durable fixation of the ceramic substrate in the exhaust line. For this reason, the correct choice of support mat material and the method of its installation inside the housing affect the proper functioning of the entire exhaust aftertreatment system. The main function of the support mat in a catalytic converter is to keep the core in the proper position and its protection against various types of internal and external damage. According to the modern requirements, assumed reliability and effectiveness of catalytic converters is from 10 to 15 years. During this period heat load and capacity of channels in the core should not be subject to significant changes. In practice however, the durability of catalytic converter is dependent on many different structural and operational factors. In this regard one of the most important elements that are responsible for the proper operation of the catalytic converter is support mat wrapped around the core in the housing. Therefore any research and development related to this topic is appropriate and very important. There is also a great demand for this research in the automotive industry.

\section{Nomenclature}
AES alcaline earth silicates
$\mathrm{CO}$ carbon monoxide
DPF diesel particulate filter
DOC diesel oxidation catalyst
GBD gap bulk density
GPF gasoline particulate filter
HAZ heat affected zone

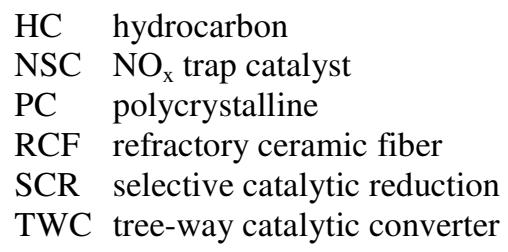

\section{Bibliography}

[1] KOZŁOWSKI, M. Mechanik pojazdów samochodowych. Budowa i eksploatacja pojazdów. Część 1. Wrocław, 2003.

[2] Wszystko o spalinach. SmartDriver.pl. www.smartdriver.pl (accessed: 02.01.2016).

[3] Zwalczanie emisji szkodliwych składników spalin. www.czasopismologistyka.pl (accessed: 06.01.2016).

[4] Tenneco Inc. - Factory information materials.

Magdalena Kozioł-Jarosz, MEng. - Rybnik Engineering Center (REC) Clean Air Europe. Tenneco Automotive Polska Sp. z o. o.

e-mail: MKoziolJarosz@tenneco.com
[5] MYSZKOWSKI, S. Układy wylotowe silników. Kompendium wiedzy praktycznej. Dodatek techniczny do Wiadomości Inter Cars S.A. 2009, 33.

[6] BRZEŻAŃSKI, M., RYBARZ, M. Tworzenie się i oddziaływanie kondensatu w układzie wylotowym silnika spalinowego. Wydawnictwo Politechniki Krakowskiej, Kraków 2014.

[7] FILIPECKA, K., PAWLIK, P., WYSŁOCKI, J., GĘBARA, P. Nowoczesne metody wytwarzania materiałów amorficznych. dlibra.bg.ajd.czest.pl (accessed: 06.01.2017).

Marek Brzeżański, DSc., DEng. - Faculty of Mechanical Engineering at Cracow University of Technology.

e-mail:MBrzez@pk.edu.pl

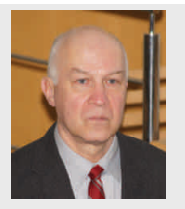

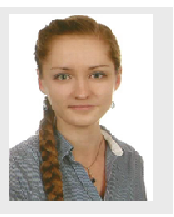

